\title{
3 Research Suare

\section{Post-exercise Stretching Protects Strain of Knee Joint Movement System by Relieving Knee Pain and Iliotibial Band Tension}

Le Yin

The First People's Hospital of Xiaoshan District

Li-ming Zhu

The First People's Hospital of Xiaoshan District

Yeqi Zhou

The First People's Hospital of Xiaoshan District

Hai-tao Ma ( $\sim$ Titaijiankang123@163.com )

The First People's Hospital of Xiaoshan District

\section{Research Article}

Keywords: Knee pain, lliotibial band, Post-exercise stretching

Posted Date: October 5th, 2021

DOI: https://doi.org/10.21203/rs.3.rs-954348/v1

License: (c) (i) This work is licensed under a Creative Commons Attribution 4.0 International License.

Read Full License 


\section{Abstract}

Background Studies have reported that exercise stretching therapy has a certain effect on improving knee joint pain and knee joint function. However, few studies have compared the effects of post-exercise stretching and non-stretching on strain of knee joint movement system. The purpose of this study is to observe the influence of whether people have stretched after exercise on knee joint pain and iliotibial band tension, and to compare the difference between the stretched group and the unstretched group after exercise for further discussion.

Methods Collecting data analysis of 71 people who love sports in the First People's Hospital of Xiaoshan District from December 2019 to October 2020, including the non-stretching group after exercise (group A, $\mathrm{n}=40$ ) and post-exercise stretching Group (Group B, n=31), compare the differences in knee pain and iliotibial band tension between the two groups and analyze the relationship between this difference and stretching.

Results The incidence of knee pain and iliotibial band tension in group A was significantly higher than that in group $\mathrm{B}(P<0.05)$. The risk of knee pain in group A was 2.940 times greater than that in group $\mathrm{B}$. The incidence of iliotibial band tension in group A was 4.190 times higher than that in group B.

Conclusions 1. People who do not stretch after exercise are at higher risk of knee pain than those who stretch. 2. People who do not stretch are more likely to develop iliotibial band tension than those who stretch. 3. Stretching after exercise helps to relieve the stiffness of the iliotibial band, maintain the stability of the knee joint, and reduce the occurrence of knee pain.

\section{Background}

Nowadays, people are paying more and more attention to the concept of health. Among them, exercise has an important impact on health ${ }^{[1]}$.Exercise can not only enhance physical fitness, prevent and treat certain diseases ${ }^{[28,29]}$,but also improve people's sleep quality and fatigue ${ }^{[27]}$. Effective stretching can also be used as an exercise therapy to treat body pain and improve physical function ${ }^{[5,24,33]}$,but modern people do not pay attention to stretching after exercise and lack relevant knowledge. Research reports that stretching exercises are of great significance to range of motion and physical performance ${ }^{[21,26]}$. Stretching activities can effectively relieve muscle fatigue and improve muscle flexibility ${ }^{[2,25]}$. Stretching after exercise can not only increase the range of exercise and reduce stiffness, but also help strength recovery and improve delayed muscle soreness ${ }^{[22]}$. In sports, people who stretch are usually more

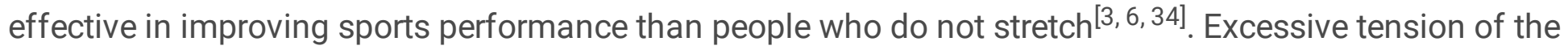
iliotibial band and knee joint pain are common phenomena in today's society. Continuous tension of the iliotibial band can cause lliotibial Band Friction Syndrome and cause knee pain. Studies have reported that exercise therapy has a certain effect on knee pain and knee joint function ${ }^{[4,23]}$. However, there are few studies comparing the effects of stretching and non-stretching after exercise on the improvement of 
the two. Therefore, it is discussed whether post-exercise stretching can improve the effect and provide a reference for basic research in sports medicine.

\section{Methods}

\section{Research objects selection}

The study collected 71 people who volunteered to participate in the posture study from December 2019 to October 2020 in the First People's Hospital of Xiaoshan District, divided them into 2 groups according to whether there was stretching after exercise. Knee pain and iliotibial band test were investigated, and statistical analysis was performed. The measurement data was completed by the same senior physician.

\subsection{Inclusion criteria:}

1) The survey population has no history of related diseases and operations;

2) There is no statistical difference in age between the two groups;

3) Sign informed consent;

4) People who insist on exercise for a long time;

\subsection{Exclusion criteria:}

1) Excluding knee joint diseases;

2) Except for the history of related operations such as hip joint and knee joint;

3) Excluding obesity BMl> 28 and pregnant women;

4) Excluding other related factors of disease;

2 Measurement methods: The degree of knee pain was judged by the VAS score scale after the doctor asked the medical history. Inspection method of iliotibial band test: To judge the tension of the iliotibial band through the Thomas test, the hip joint cannot reach $0^{\circ}$ indicating that the iliopsoas muscle is tense. When the hip joint is $0^{\circ}$, the knee joint is greater than $90^{\circ}$, reflecting the tension of the rectus femoris, keeping the hip joint adduction and abduction $0^{\circ}$ and let it fall naturally from a high place. If the leg is raised, it means that the iliotibial band is tight.

\section{Statistical analysis method}

SPSS 16.0 statistical software is used for data processing in the data analysis of this study. MannWhitney test is used to compare the age of two groups of people.Chi-square test is used to compare the incidence of knee pain, iliotibial band tension, and gender differences. Relevant risk assessment adopts logistic regression analysis. $P<0.05$ considered the difference to be statistically significant. 


\section{Results}

Studies have investigated that approximately $25 \%$ of adults in the world often suffer from knee joint pain, which affects the quality of life and limits the function and range of motion of the knee joint ${ }^{[31]}$.

All study subjects are from people who volunteered to participate in the posture study from December 2019 to October 2020.A total of 112 volunteers are selected for this study. After the inclusion and exclusion criteria, 71 volunteers are finally included to participate in the research survey. Among them, 35 are males and 36 are females. According to whether they stretched after exercise, they are divided into 40 people in group $A$ and 31 people in group $B$. The age of group $A$ is $42.88 \pm 10.05$ years old, and the age of group $B$ is $41.42 \pm 8.78$ years old. Basic information of the two groups are shown in Table 1 .

Table 1

Basic information of the two groups

\begin{tabular}{|llll|}
\hline Group & \multicolumn{2}{l}{ Gender } & \multirow{2}{*}{$\operatorname{Age}(\mathbf{x} \pm \mathbf{s})$} \\
\cline { 2 - 3 } & Male & Female & \\
\hline A Group 40 cases & 21 & 19 & $42.88 \pm 10.05$ \\
\hline B Group 31 cases & 14 & 17 & $41.42 \pm 8.78$ \\
\hline
\end{tabular}

Through the analysis of the research results in Table 2 and Table 3, There is no statistical difference in age and gender between the two groups ( $P>0.05$ ), the incidence of knee pain and iliotibial band tension between the two groups is statistically different $(P<0.05)$. The incidence of knee pain in group $A$ is significantly higher than that in group $B$. The incidence of iliotibial band tension in group A is significantly higher than that in group B. Logistic regression analysis is used to analyze the relative risks of various indicators between the two groups. It is concluded that the risk of knee pain in group $A$ is 2.940 times higher than that in group $B$, and the risk of iliotibial band tension in group $A$ is 4.190 times higher than that in group $B$.

Table 2

Compare the differences of various indicators between the two groups

\begin{tabular}{|c|c|c|c|c|c|c|c|}
\hline \multirow[t]{2}{*}{ Group } & \multicolumn{2}{|c|}{ Knee pain } & \multicolumn{2}{|c|}{ Iliotibial band tension } & \multicolumn{2}{|c|}{ Gender } & \multirow{2}{*}{$\begin{array}{l}\text { Age } \\
M(P 25, P 75)\end{array}$} \\
\hline & Y & $\mathrm{N}$ & Y & $\mathrm{N}$ & $M$ & $\mathrm{~F}$ & \\
\hline A Group 40 cases & 26 & 14 & 22 & 18 & 21 & 19 & $43(32,51)$ \\
\hline B Group 31 cases & 12 & 19 & 7 & 24 & 14 & 17 & $46(30,49)$ \\
\hline Statistics & \multicolumn{2}{|c|}{$\chi^{2}=4.85$} & \multicolumn{2}{|c|}{$\chi^{2}=7.60$} & \multicolumn{2}{|c|}{$\chi^{2}=0.38$} & $Z=1.14$ \\
\hline$P$-value & \multicolumn{2}{|c|}{0.028} & \multicolumn{2}{|c|}{0.006} & \multicolumn{2}{|c|}{0.540} & 0.252 \\
\hline
\end{tabular}


Table 3

The relative risks of various indicators between the two groups

\begin{tabular}{|llll|}
\hline & \multicolumn{3}{l|}{ Logistic Regression Analysis } \\
\hline & $H R$ & $95 \% \mathrm{Cl}$ & $P$-value \\
\hline Knee pain & 2.940 & $1.113-7.771$ & 0.030 \\
\hline Iliotibial band tension & 4.190 & $1.470-11.943$ & 0.007 \\
\hline
\end{tabular}

\section{Discussion}

Knee joint damage is a common symptom in strain of movement system. The knee joint is an important joint of the lower limbs, allowing it to move between the femur, tibia and patella. The knee joint is a modified hinge joint that participates in a variety of motion functions of the lower limbs ${ }^{[30]}$.Knee joint pain has become a common clinical symptom that plagues people of all ages in society, and the risk of knee joint pain is mostly related to external environmental damage and own factors ${ }^{[13,14]}$. For the treatment of knee joint pain, there are various treatment methods such as surgery, medication and physical therapy $[24,15,16,35]$. The literature reports that exercise therapy can be used as an intervention to treat knee osteoarthritis ${ }^{[7]}$. This is based on the principle that exercise therapy can increase joint stability and flexibility and reduce pain, thereby optimizing functional capacity and independence. Exercise therapy can significantly improve pain and function ${ }^{[8]}$. Stretching after exercise can further provide a beneficial effect on the knee joint and its surrounding tissues ${ }^{[9]}$.

The iliotibial band is the thickened part surrounding the fascia lata of the thigh. It originates from the iliac crest. The lower end is attached to the lateral tibial condyle, fibular head and joint capsule of knee. It has the function of maintaining the stability of the knee joint. When the disease occurs, it can cause related knee joint pain ${ }^{[17,18]}$.It has been reported in the literature that knee joint pain is related to lliotibial Band Friction Syndrome.lliotibial Band Friction Syndrome is one of the many causes of knee pain.Various types of sports can cause it to occur. The incidence of runners and other sports athletes is $1.6-12 \%$ ${ }^{[32]}$.Various factors in the exercise process can cause the iliotibial band to be tight and can cause the pathological changes related to the iliotibial band.Long-term iliotibial band tension can cause lliotibial Band Friction Syndrome and ultimately lead to the occurrence of knee pain, and relaxation of the iliotibial band through stretching exercises can effectively improve knee joint pain ${ }^{[10,11]}$. There are usually surgical and non-surgical treatments for the treatment of lliotibial Band Friction Syndrome, and stretching can also be used as a non-surgical treatment for lliotibial Band Friction Syndrome ${ }^{[11,12]}$. The tense iliotibial band can be relaxed by proper stretching method, so as to achieve the purpose of treatment.

This study takes stretching as an important influencing factor, analyzes the effect of stretching on the knee joints of sports people, and provides a reference for improving the quality of sports and reducing related injuries.Due to limited time and financial resources, there are some problems as follows. First of 
all, it is impossible to conduct detailed retrospective interviews and add more testing indicators.Secondly, there is a lack of relevant tests for the correctness and effectiveness of the patient's stretching, so it is impossible to analyze the situation of each patient more comprehensively.In addition, the influence of psychological factors on exercise ${ }^{[19]}$ and the influence of different exercise types on knee symptoms should also be considered ${ }^{[20]}$.Further research is needed in the future to investigate the influence of these factors on the knee joint.Finally, this study has a lot of room for improvement, and more testing items can be added in the future to analyze the impact of stretching on the sports crowd.

\section{Conclusions}

Based on the comparison of the incidence of knee pain and iliotibial band tension and related risk analysis of the above two sets of data, it can be concluded that stretching after exercise is better for knee pain and iliotibial band tension than without stretching after exercise. Stretching after exercise can reduce the risk of knee pain and iliotibial band tension in the crowd. Stretching after exercise can more effectively prevent knee pain and maintain the flexibility of the iliotibial band, maintain the function of the iliotibial band, stabilize the knee joint, and reduce related knee pain caused by the disease of the iliotibial band. For those people who insist on physical exercise for a long time, stretching is a very good way to prevent the occurrence of sports injury diseases. Stretching can not only improve athletic ability and promote physical health, but also can effectively relieve muscle fatigue and tension through stretching. At the same time, it also has a certain therapeutic effect on some sports injuries. It is worth popularizing among the sports crowd.

\section{Declarations}

\section{Ethics approval and consent to participate}

All participants read and signed a written informed consent prior to the start of this study. In compliance with relevant Chinese laws and regulations, the trial was conducted in accordance with the Declaration of Helsinki and the International Ethical Guidelines for Biomedical Research Involving Human Subjects and the ethical principles of China's ethical review methods for biomedical research involving humans.This study was approved by the Medical Ethics Committee of The First People's Hospital of Xiaoshan District on November 28, 2019.(Approval NO: Lun Shen Zi (Section) 2019 No. 36)

\section{Consent for publication}

Not applicable

\section{Availability of data and materials}

Due to the large amount of personal privacy involved, the data and materials in this study are not disclosed. However, the data are available from the corresponding author on reasonable request. 


\section{Competing interests}

The authors declare that they have no competing interests.

\section{Funding}

The research was supported by the Xiaoshan District Science and Technology Association. The funding is mainly used for purchasing equipment and hiring related technical personnel.

\section{Authors' contributions}

$\mathrm{LY}$ is responsible for the overall conception and design of this manuscript. LMZ is responsible for the data collection.YQZ is responsible for the questionnaire. HTM developed the design of the study. All authors read and approved the final manuscript.

\section{Acknowledgements}

We thank the sports medicine team for their important efforts in identifying and recruiting participants.

\section{Authors' information}

Le Yin, male, surgeon, master of medicine, research direction: sports medicine, (email) remind0104@126.com

\section{References}

1. Marie Clare · Grant,Julien S · Baker,et al.An Overview of the Beneficial Effects of Exercise on Health and Performance. Adv Exp Med Biol.2020; 1228: 3-22.

2. Kieran O'Sullivan, Elaine Murray,David Sainsbury. The effect of warm-up, static stretching and dynamic stretching on hamstring flexibility in previously injured subjects.BMC Musculoskeletal Disorders.2009;10:37

3. Rolf Adelsberger,Gerhard Tröster.Effects of stretching and warm-up routines on stability and balance during weight-lifting: a pilot investigation. BMC Research Notes. 2014;7:938.

4. Grazielle Cordeiro Aguiar,Marcela Rêgo Do Nascimento,et al. Effects of an exercise therapy protocol on inflammatory markers, perception of pain, and physical performance in individuals with knee osteoarthritis.Rheumatol Int.2015;35(3):525-531.

5. Adriana P. FONTANA CARVALHO,Sébastien S. DUFRESNE,et al.Effects of lumbar stabilization and muscular stretching on pain, disabilities, postural control and muscle activation in pregnant woman with low back pain.European Journal of Physical and Rehabilitation Medicine.2020;56(3):297-306. 
6. Piotr · Zmijewski,Patrycja - Lipinska,et al.Acute Effects of a Static Vs. a Dynamic Stretching Warm-up on Repeated-Sprint Performance in Female Handball Players.Journal of Human Kinetics. 2020; 72: 161-172.

7. Thomas Bestwick-Stevenson,et al.Association of Sports Participation With Osteoarthritis: A Systematic Review and Meta-Analysis.Chendu: Orthop J Sports Med. 2021;9(6):2325-9671.

8. Smith T, Kirby E, Davies L. A systematic review to determine the optimal type and dosage of landbased exercises for treating knee osteoarthritis. Phys Ther Rev. 2014;19(2):105-113.

9. Lucia Helena - Batista,et al.Active stretching improves flexibility, joint torque, and functional mobility in older women. Am J Phys Med Rehabil.2009;88(10):815-22.

10. Lavine R,et al.lliotibial band friction syndrome,Curr Rev Musculoskelet Med.2010;3(1-4):18-24.

11. Khaund R, et al.Flynn SH, lliotibial band syndrome: a common source of knee pain. Am Fam Physician.2005;71(8):1540-50.

12. Strauss EJ,et al.Iliotibial band syndrome: evaluation and management. J Am Acad Orthop Surg.2011;19(12):728-36.

13. Ingham SL,et al.Incident knee pain in the Nottingham community: a 12-year retrospective cohort study. Osteoarthritis Cartilage.2011;19(7):847-52.

14. Miranda $\mathrm{H}$,et al.A prospective study on knee pain and its risk factors. Osteoarthritis Cartilage.2002;10(8):623-30.

15. Bijan FOROGH,Elaheh MIANEHSAZ,et al.Effect of single injection of platelet-rich plasma in comparison with corticosteroid on knee osteoarthritis: a double-blind randomized clinical trial. The Journal of Sports Medicine and Physical Fitness. 2016;56(7-8):901-8.

16. Skou ST,et al.The effects of total knee replacement and non-surgical treatment on pain sensitization and clinical pain. Eur J Pain.2016;20(10):1612-1621.

17. Terry GC,et al.The anatomy of the iliopatellar band and iliotibial tract. Am J Sports Med. 1986;14(1):39-45.

18. Flato R,et al.The iliotibial tract: imaging, anatomy, injuries, and other pathology. Skeletal Radiol. 2017;46(5):605-622.

19. Annika Taulaniemi, Markku Kankaanpää, et al. Fear-avoidance beliefs are associated with exercise adherence: secondary analysis of a randomised controlled trial (RCT) among female healthcare workers with recurrent low back pain.BMC Sports Science, Medicine and Rehabilitation.2020;12:28.

20. Lloyd L. Y. Chan,et al.Associations between sport participation and knee symptoms: a crosssectional study involving 3053 undergraduate students. BMC Sports Science, Medicine and Rehabilitation.2020;12:20.

21. David G Behm,Anthony J Blazevich,et al.Acute effects of muscle stretching on physical performance, range of motion, and injury incidence in healthy active individuals: a systematic review. Appl Physiol Nutr Metab.2016;41(1):1-11. 
22. José Afonso,Filipe Manuel Clemente,Fábio Yuzo Nakamura,et al.The Effectiveness of Post-exercise Stretching in Short-Term and Delayed Recovery of Strength, Range of Motion and Delayed Onset Muscle Soreness: A Systematic Review and Meta-Analysis of Randomized Controlled Trials. Front Physiol.2021; 5;12:677581.

23. Shirin Assar,Farzaneh Gandomi,et al.The effect of Total resistance exercise vs. aquatic training on self-reported knee instability, pain, and stiffness in women with knee osteoarthritis: a randomized controlled trial. BMC Sports Science, Medicine and Rehabilitation.2020; 12: 27.

24. Tiina Freimann,Eda Merisalu,Mati Pääsuke,et al.Effects of a home-exercise therapy programme on cervical and lumbar range of motion among nurses with neck and lower back pain: a quasiexperimental study.BMC Sports Science, Medicine and Rehabilitation.2015;7:31.

25. Ana Assumpção,Luciana A Matsutani,et al.Muscle stretching exercises and resistance training in fibromyalgia: which is better? A three-arm randomized controlled trial.Eur J Phys Rehabil Med.2018;54(5):663-670.

26. Ewan Thomas,Antonino Bianco,et al.The Relation Between Stretching Typology and Stretching Duration: The Effects on Range of Motion.Int J Sports Med.2018;39(4):243-254.

27. Maryam Ezati,Maryam Keshavarz,et al.The effect of regular aerobic exercise on sleep quality and fatigue among female student dormitory residents.BMC Sports Science, Medicine and Rehabilitation. $2020 ; 5 ; 12: 44$.

28. Carol Ewing Garber, Bryan Blissmer,et al.American College of Sports Medicine position stand. Quantity and quality of exercise for developing and maintaining cardiorespiratory, musculoskeletal, and neuromotor fitness in apparently healthy adults: guidance for prescribing exercise.Med Sci Sports Exerc.2011;43(7):1334-59.

29. Christina M Dieli-Conwright,Kerry S Courneya,et al. Aerobic and resistance exercise improves physical fitness, bone health, and quality of life in overweight and obese breast cancer survivors: a randomized controlled trial.Breast Cancer Res.2018;19;20(1):124.

30. Enrico Vaienti,Giacomo Scita,et al.Understanding the human knee and its relationship to total knee replacement.Acta Biomed. 2017;7;88(2S):6-16.

31. Nguyen US, Zhang Y, Zhu Y, Niu J, Zhang B, Felson DT. Increasing prevalence of knee pain and symptomatic knee osteoarthritis: survey and cohort data. Ann Intern Med. 2011;06;155(11):725-32.

32. Strauss EJ, Kim S, Calcei JG, Park D. Iliotibial band syndrome: evaluation and management. J Am Acad Orthop Surg. 2011 Dec;19(12):728-36.

33. Tahran Ö, Yeşilyaprak SS. Effects of Modified Posterior Shoulder Stretching Exercises on Shoulder Mobility, Pain, and Dysfunction in Patients With Subacromial Impingement Syndrome. Sports Health.2020;12(2): 139-148.

34. Mohamed FRIKHA, Nesrine CHAÂRI,et al.Acute effect of stretching modalities and time-pressure on accuracy and consistency of throwing darts among 12- and 13-year-old schoolboys. The Journal of Sports Medicine and Physical Fitness.2017;57(9):1089-97. 
35. Lasun O Oladeji,et al.Cooled Radio Frequency Ablation for the Treatment of Osteoarthritis-Related Knee Pain: Evidence, Indications, and Outcomes. J Knee Surg.2019;32(1):65-71. 